\title{
Suicidal behaviour and quality of life in Slovene prisons (working title)
}

Nuša Zadravec Šedivy, Diego De Leo, Vita Poštuvan, Gregor Žvelc

\begin{abstract}
Prisoners are an extremely vulnerable group in regard to suicidal behaviour, with consistently higher prevalence of suicide when compared to the general population. However, characteristics of suicidal behaviour for this group are understudied in Slovenia. We wanted to investigate characteristics of suicidal behaviour and suicide-related factors in male prisoners of this country and recruited to the purpose 419 male prisoners. These individuals filled-in a package of questionnaires which included demographic characteristics, medical history, WHOQOL-BREF, Five Well-Being Index, Paykel's questions on suicidal behaviour, Depression, Anxiety and Stress scale, and the Interpersonal Needs questionnaire. Study results showed that $10.3 \%$ of participants reported being at current risk for suicide, with these inmates reporting more severe mental health problems, lower quality of life and lower well-being levels. Lack of social contacts did not affect mental health as much as quality of social support, where perceived belongingness and acceptance by other represented a protective factor for suicidal behaviour.
\end{abstract}

\section{Keywords}

suicide, quality of life, mental health, prison, male 


\section{Introduction}

Prison is a specific environment, both in terms of population and in terms of factors that impact the health of prisoners. In general, prisoners represent a very vulnerable population with increased health care needs compared to the general population. Special conditions such as stress, violence and lack of interventions addressing harmful health habits are reflected in the high rate of transmission of infectious diseases, increasing the vulnerability of developing some other diseases and an increased risk of developing or worsening mental disorders (Nobile, Flotta, Nicotera, Pileggi, \& Angelillo, 2011).

All these factors influence the quality of life in prison. According to the World Health Organization, quality of life represents an individual's subjective assessment of perceived living conditions that relates to the specific cultural setting (WHO, 1996). It covers physical, psychological and social relations aspects, as well as environmental factors (Nobile et al., 2011). In terms of physical health, most prisoners come from poor and vulnerable social groups, which is also reflected in a greater exposure to different diseases than the general population. A high risk of HIV, hepatitis B and C, and tuberculosis has been signalled in prisoners (WHO, 2013). With a greater transmission of infectious diseases, the prevalence of other diseases is also higher among the prisoners than in the general population: e.g., cardiovascular diseases and some types of cancer (Togas, Raikou, \& Niakas, 2014). Prison environment (e.g., lack of space, sanitation, light and fresh air) and shortage of trained personnel also concur to impact health conditions of jail inmates.

Mental health problems can pre-exist to imprisonment, or can develop or worsen in jail (Carcedo, Perlman, López, \& Orgaz, 2012). Social context of imprisonment often leads to a high rate of mental ill health in the prison population (Nurse, Woodcock, \& Ormsby, 2003). A systematic review of surveys of people in general prison populations in western countries suggested that one in seven prisoners have psychotic illnesses or major depression, and about one in two male prisoners have antisocial personality disorders (Fazel \& Danesh, 2002). This indicates that the risk of having serious psychiatric disorders is substantially higher in prisoners than in the general population.

For prison inmates is problematic to have a satisfying romantic and sexual relation while imprisoned. It is also difficult to maintain relationships with the loved ones, including friends and family (Biggam \& Power, 1997; Carcedo et al., 2012; Carcedo, Perlman, Orgaz, López, \& Fernández-Rouco, 2011). Carcedo and associates (2008) found that social and sexual relationships were the most important needs for inmates' psychological health.

Prison environment is characterized by several specific factors, such as overcrowded environments, violence, isolation, loss of freedom, substance abuse and lack of medical services that may adversely affect individuals' health, thus increasing the risk of suicide (Konrad et al., 2007). In fact, the prevalence of suicide is consistently higher in prison compared to the prevalence of suicide in the general population, with most countries reporting around 100-150 suicide cases per 100,000 (Barker, Kõlves, \& De Leo, 2014).

The research on prison suicide in Slovenia made by National Prison Administration in 2003 showed that self-killing is the most frequent cause of death in Slovenian prisons (Prison Administration of the Republic of Slovenia, 2003). In Slovenia, between the years 1995 and 2016 the rate of suicide was twelve times higher than the rate among the rest of Slovene population; for an average prison 
population around 1,400 inmates, there were 118 death cases, 50 of which due to suicide (Zver Makovec \& Madjar, 2017). Between 2002 and 2016 there were on average 15.6 suicide attempts and 72.9 self-injury cases per year (URSIKS, 2017). The most common suicide method used in Slovenian prisons is hanging $(76.67 \%)$, followed by overdose $(16.67 \%)$ and cuts (6.67 \%) (Poštuvan \& Madjar, 2013). The majority of suicide deaths occurs in pre-trial detainees. Since pre-trial detainees represent only around $15 \%$ of all prison population in Slovenia, they are the most at risk population among prison inmates (URSIKS, 2017).

Suicide is a significant indicator of mental ill health. However, the Slovene prison system does not have precise data on the prevalence of mental disorders in prisons, as there is no system in operation to gather and report these data (Poštuvan \& Madjar, 2013). Nonetheless, the EUPRIS study (Salize, Dreßing, \& Kief, 2007) showed that, according to ICD-10, neurotic, stress-related and somatoform disorders were the most frequent in Slovene prisons. This was followed by mental and behavioural disorders due to psychoactive substance use, disorders of adult personality and behaviour, mood disorders, behavioural syndromes associated with physiological disturbances, and physical factors. Since 2012, the prisoners with mental disorders at high risk of suicide are being relocated to the Unit for Forensic Psychiatry. This way, 24-hour psychiatric care is provided for them (Poštuvan \& Madjar, 2013), which seems to be an effective preventive strategy regarding suicide.

However, prisoners, especially males, are still an extremely vulnerable group in Slovenia, where the prevalence of suicide is consistently higher compared to the prevalence of suicide in the general population (Zver Makovec \& Madjar, 2017) but characteristics of suicidal behaviour in this group are still understudied in Slovenia. The aim of this study it therefore to investigate characteristics of suicidal behaviour in male prisoners and to gain better insight into suicide-related factors, such as mental health, quality of life, the nature and quantity of interpersonal relationships, and availability of preventive interventions specific for the prison environment. 


\section{Method}

\section{Participants}

The sample included 419 male prisoners from all six prisons of Slovenia, which represents one-third of all prisoners in Slovenia. Sixty nine (16.5\%) of all participant were detained individuals, and 335 (80.0\%) were convicted prisoners; 15 (3.6\%) didn't report their status. Time of serving a sentence varied from 1 to 360 months $(M=42.89, S D=48.79)$. Regarding suicidal behaviour, $83(19.8 \%)$ participants reported previous suicide attempt(s).

Participants came from all 12 statistical regions of Slovenia; however, the majority 108 (25.8\%) came from Central Slovenia. Regarding living environment, 192 (43.3\%) participants came from bigger cities (city municipalities), 88 (19.9\%) from a smaller city, and 88 (19.9\%) from rural areas; 74 (16.7\%) did not report their living environment.

The majority of prisoners participating to this research reported low levels of education, since 131 (31.3\%) achieved compulsory basic education or less, 162 (38.7\%) completed secondary vocational and technical education, 77 (18.4\%) achieved general secondary education, and 41 (9.8\%) achieved post-secondary vocational education or higher; 8 (1.9\%) participants, did not report their educational level. Regarding marital status, 187 (44.6\%) of participants reported being single and 223 (53.2\%) reported being in a relationship; 9 (2.1\%) did not report their marital status. Of all male prisoners participating in the research, 220 (52.5\%) reported having children and 188 (44.9\%) reported not having them; 11 (2.6\%) participant did not report whether they have children or not.

\section{Instruments}

We collected data on demographic characteristics, medical history and psychosocial characteristics of participants and we administered the following instruments:

WHOQOL-BREF (WHO, 1996), which assesses the individual's perceptions of life quality in the context of own culture and value systems, personal goals, standards and concerns. The instrument contains a total of 26 questions. Each item is rated on a 5-point Likert scale. Questions measure four domains regarding the quality of life (physical health, psychological health, social relationships, and environment), individual's overall perception of quality of life and individual's overall perception of their health. Higher scores denote higher quality of life. Internal consistency of the questionnaire in our research ranged from $\alpha=0.57$ to 0.82 , demonstrating good internal consistency.

Five well-being index - WHO-5 (WHO, 1998), which is a self-report measure of current mental wellbeing. It consists of five statements, which respondents rate on a 6-point Likert scale. The total raw score, ranging from 0 to 25 , is multiplied by 4 to give the final score, with 0 representing the worst imaginable well-being and 100 representing the best imaginable well-being. In our sample, Cronbach $\alpha$ value was 0.93 , demonstrating very good internal consistency.

Paykel's scale of suicidal behaviour - PSS (Paykel, Myers, Lindenthal, \& Tanner, 1972), which is a 5item interview that assesses past history of thoughts of death, suicide ideation, and suicide attempt over the past two weeks. Respondents answer the first four questions on a 6-point Likert scale. On the question regarding previous suicide attempt, the person chooses one of the following options: 1 - yes, in the last two weeks, 2 - yes, in the last six months, 3 -yes, in more than 6 months, or $4-$ no, never. In our research internal consistency of the scale was very good, with Cronbach $\alpha=0.90$. 
Depression, anxiety and stress scale - DASS21 (Lovibond \& Lovibond, 1995), which is a 21-item selfreport measure, rating the frequency and severity of negative emotions and feelings of depression, anxiety and stress over the previous week on a series of 4-point scales. In our sample, internal consistency was 0.87 for depression subscale, 0.90 for anxiety subscale and 0.93 for stress subscale, overall demonstrating a good internal consistency.

Interpersonal needs questionnaire - INQ (Van Orden et al., 2010), which assesses thwarted belongingness and perceived burdensomeness. Items are rated via self-report on a 7-point Likert scale and composite scores are computed as mean scores across each subscale, with scores ranging from 1 to 7. In our sample, the internal consistency of the scale was $\alpha=0.92$ for perceived burdensomeness subscale and $\alpha=0.72$ for thwarted belongingness subscale.

\section{Procedure}

We recruited participants on the basis of a cooperation agreement with the National Administration for the Execution of Punishment. This agency disseminated information about the research project to coordinators from all six prisons of Slovenia. Coordinators invited to participate all prisoners who speak Slovene and are not included only in the weekend prison program, which means that they were serving the sentence inside prison facilities also during work days.

Research was conducted between May 2016 and March 2017 and was held in all 6 prison facilities in Slovenia. The questionnaire was administered to small groups of up to 15 participants in group activity rooms. All participants were informed about the objectives of the study and signed an informed consent. Filling-in of questionnaires took up to 1 hour. During the administration of the questionnaire, support was offered to participants (e.g. explanation of questions meaning; help with reading). Participants had the possibility of talking to researchers, if needed.

\section{Analysis of data}

To control quality of data entry and avoid random mistakes double data entry was performed. IBM SPSS Statistics (21.0 edition) was used to run bivariate and multivariate analyses. For data on suicidal behaviour in prison and related factors, we used descriptive statistics (e.g. $M, S D$ and $f$ ). We used $\chi^{2}$ to analyse categorical data regarding differences in suicidal behaviour between detained and convicted prisoners, as well as differences in social relations and help accessibility between prisoners at risk or not at risk for suicide. Further, for comparing means between prisoners at current risk and prisoners not at risk for suicide on different scales, we used independent $t$-test and Mann-Whitney $U$ test; and for comparing means on different scales of several groups, according to changes in social contacts, we used ANOVA. To analyse the correlation between different items and scales, we used Spearman's $\rho$ correlation.

\section{Results}

With regards to the prevalence of suicidal behaviour in prisoners, $83(19.8 \%)$ of prisoners reported having previously attempted suicide. In addition, we found that $43(10.3 \%)$ of participants were at current risk for suicide based on scores at the PSS scale. One hundred and three participants (24.6\%) 
reported having some kind of physical or mental health problem before incarceration, with 94 prisoners (22.4\%) reporting current presence of health problems.

We further compared frequency and severity of negative emotions and feelings of depression, anxiety and stress between prisoners at risk for suicide and those not at risk, using Mann-Whitney $U$ test. Table 1 shows that prisoners who were at current risk for suicide reported significantly $(p<0.05)$ more frequent or severe feelings of depression, anxiety and stress than prisoners who were not at current risk for suicide.

- $\quad$ Please, insert Table 1 near here -

\section{Association between suicidal behaviour and quality of life and well-being in prison}

We analysed whether there wass any difference in perceived quality of life in prison and mental wellbeing between those prisoners who were at current risk for suicide and those who were not, using independent t-test.

On average, prisoners who were at current risk for suicide reported lower quality of life regarding physical health, psychological health, social relations, environment, overall perception of quality of life as well as overall perception of their health, as shown in Table 2. Differences were significant for all domains regarding quality of life. However, this represented a medium size effect for overall perception of quality of life $r=0.32$, and a small size effect for all other domains.

- Please, insert Table 2 near here -

Table 2 shows that prisoners who were at current risk for suicide reported lower mental well-being $(M=33.30, S D=26.62)$ in comparison to prisoners who were not at current risk for suicide $(M=$ $60.67, \mathrm{SD}=24.32)$. This difference was significant $\mathrm{t}(399)=6.901, \mathrm{p}<0.05$, and represented a medium size effect: $r=0.33$.

\section{Association between suicidal behaviour and social relations in prison}

We analysed whether changes in social contacts of prisoners, while in prison, were associated with their reported suicidal behaviour. In regard to changes in social contacts, 205 participants (48.9\%) reported having less social contacts with family and close friends; 169 (40.3\%) reported that amount of their social contacts remained the same that it was before incarceration, and 31 of all participants (7.4\%) reported having more social contacts. Fourteen participants (3.3\%), who did not report on changes in social contacts, were excluded from further analysis.

On average, prisoners that reported having less social contacts in prison than they had before, had the highest scores on item 1 of the PSS scale, which concerns feelings that life is not worth living ( $M=$ $0.82, \mathrm{SD}=1.25)$; on item 2 of the PSS scale, which regards wishes to be dead ( $M=0.73, S D=1.37$ ); on item 3 on the PSS scale: thinking about suicide ( $M=0.53, S D=1.12)$; and on item 4 of the PSS scale: seriously considering taking own life or making plans about it $(M=0.46, S D=1.25)$ in comparison to prisoners who reported no changes in social contacts or more contacts, as shown on Figure1. 
- Please, insert Figure 1 near here -

Using Welch's ANOVA, we found no significant effect of changes in social contacts on score of item 1 of the PSS scale, $F(2,88.6)=2.51, p=0.08, \omega=0.08$; item 3: $F(2,86.3)=1.52, p=0.22, \omega=0.05$, and item 4 of the PSS scale, $F(2,84.1)=1.99, p=0.14, \omega=0.07$. However, there was a significant effect of changes in social contacts on scores of item 2 of the PSS scale, $F(2,87.7)=5.12, p<.05, \omega=0.14$. Ptanned contrasts further revealed that having less social contact in comparison to no changes in social contacts significantly increased score of item 2 on the PSS scale, $t(359.4)=3.00, p<0.05, r=$ 0.16 , and that less social contact in comparison to having more social contacts significantly increased score of item 1 on the PSS scale, $\mathrm{t}(44.1)=2.06, \mathrm{p}<0.05, \mathrm{r}=0.30$, and item 2 on the PPS scale, $\mathrm{t}(48.8)$ $=2.16, p<0.05, r=0.30$.

We analysed if there were differences in being at risk for suicide between prisoners who reported having friends among inmates and those who reported not having any friends in prison. There was a significant association between risk of suicide and whether or not prisoners reported having friends in prison, $\chi 2(1)=4.23, p<0.05$. The odds ratio of prisoners at risk for suicide having friends in prison was 0.51 times lower than prisoners who were not at risk for suicide.

Additionally, we analysed interpersonal needs of prisoners in association with their risk for suicide. We examined whether there was a significant difference in thwarted belongingness and perceived burdensomeness between prisoners at current risk for suicide and those who were not at such risk using Mann-Whitney $U$ test.

Figure 2 shows that prisoners who were at current risk for suicide reported higher thwarted belongingness $(M=4.30, S D=0.99)$ and perceived burdensomeness $(M=3.70, S D=1.93)$ than prisoners who were not at current risk for suicide $(M=3.60, S D=1.19 ; M=1.52, S D=0.96)$. This difference was significant for both thwarted belongingness $(U=9.63, z=3.29, p<0.05, r=0.16)$ and for perceived burdensomeness $(U=12.61, z=8.20, p<0.05, r=0.41)$.

-Please, insert Figure 2 near here - 


\section{Discussion}

Male prisoners represent an extremely vulnerable group for suicidal behaviour. In this study, $19.8 \%$ of prisoners included reported that they previously attempted suicide, which is a relatively small figure in comparison to previous research reporting that a quarter of male prisoners attempts suicide in their lifetime (Kerkhof \& Bernasco, 1990); however, in that research only detained prisoners were included. Additionally, we found that $10.3 \%$ of study participants were at current risk for suicide. Such information is in line with previous research suggesting that the prevalence of suicidal behaviour in prison is consistently higher that the prevalence in the general population (Barker, Kõlves, \& De Leo, 2014). In the Paykel et al' study (1972), out of a sample of 720 general population people, only $2.8 \%$ expressed the wish to be dead, $1 \%$ had suicide ideation, and $1 \%$ seriously considered suicide or made plans for it.

In regard to health problems however prisoners didn't report greater problems while in prison since $24.6 \%$ of prisoners reported having some kind of physical or mental health problem before they entered prison, and similarly $22.4 \%$ of participants reported having such problems while in prison. There can be different explanations for such results since the percentage of participants having previous health problem does not define in what time period before imprisonment those problems occurred and we also cannot define what percentage of health problems during incarceration occurred inside the prison. However, more than one-fifth of prisoners reported having health problems in prison, which shows that prevalence of such problems in prison is very high. This is in line with previous research reporting that most prisoners come from vulnerable social groups, which can be translated in a greater exposure to different diseases compared to the general population (WHO, 2013).

Additionally, prisoners at current risk for suicide reported significantly more frequent or severe feelings of depression, anxiety and stress in comparison to prisoners that were not at risk for suicide. Such results are also in line with previous research suggesting that depression and hopelessness present two most common psychological states at the time of a suicidal act in prison and that anxiety symptom increase that risk even further. Nearly $50 \%$ of those who die by suicide experience acute stressors at the time of the suicide, whereas most suffer from chronic stressors (White, Schimmel, \& Frickey, 2002). Depression, anxiety and stress, therefore, can represent important risk or sometimes even triggering factors in the area of mental health problems.

In addition to health and mental health problems, prison environment can be challenging regarding social interactions as well. The data we collected on social contacts in prison showed that almost half of participants reported fewer contacts, $40.3 \%$ of prisoners reported no changes in social contacts and $7.4 \%$ of participants reported more social contact while in prison in comparison to previous life. In relation to changes in social contacts, those who reported having fewer contacts then they had before incarceration, were showing significantly higher scores regarding the wish to be dead in comparison to others; however, there were no other significant differences among groups of participants that reported decrease, increase or no changes in social support regarding other suicidal behaviours and different mental health problems, e.g. feelings of depression, anxiety and stress. In addition, there was also no significant association between risk for suicide and whether or not prisoners wished to have more social contacts. These results are not in line with previous research reporting that a higher discrepancy between the emotional support received and desired, along with 
a lower actual practical and emotional support, were related to worse mental health (Biggam \& Power, 1997). Apparently, in our research, changes in social support and desire for such a support did not play an important role in the quality of mental health of prisoners. The explanation for such a discrepancy can lay in the overall low scores on scales measuring suicidal behaviour, depression, anxiety and stress of our sample.

Our results can be also associated with more distant social relations and ambivalent perception of consequences that social contacts and support might have on them. Thus, we can suggest that social contacts and support received by family and friends may in some cases lower mental well-being of prisoners. This effect of social contacts on mental health is consistent with the idea that relationships can not only be a source of positive feelings but can also cause additional tension (Schafer, 1994). Additionally, because of stigma, a prisoner can develop a feeling that others perceive him as a burden and this can also be a reason for avoiding others or experiencing less connection towards others (Rimkeviciene, Hawgood, O'Gorman, \& De Leo, 2015), which can result in a decrease of mental well-being. Similarly, in our study, prisoners with current risk for suicide in comparison to those without such risk had significantly higher scores on perceived burdensomeness and thwarted belongingness, indicating that perception on being a burden to others and not belonging is associated with higher risk for suicide among prisoners.

It seems that amount of contacts with family and friends and low discrepancy between social contacts person have and desire are not affecting prisoners' mental health as much as the quality of social support, where perceived belongingness and acceptance by other, can represent a protective factor against mental health problems and suicidal behaviour even in cases, where social contacts are less frequent. However, while individuals with close relationships with people outside the prison can rely primarily on those relationships as a source of their well-being, individuals without such relationships need to rely on other relations inside the prison that act as replacements in a compensatory manner (Carcedo et al., 2012). Such relationships in prison can be, however, also associated with better adaptation to prison environment, which consequently leads to less mental health problems and lower risk for suicide.

Physical health, psychological aspects, social relations and environmental factors contribute to individual's subjective assessment of the perceived quality of life (Nobile et al., 2011). In our study, prisoners who were at current risk for suicide consistently reported lower quality of life in different areas, which included a more negative overall perception of quality of life, more negative perception of their overall health, as well as lower quality of physical and psychological health, social relations and environment. In addition, also significantly lower mental well-being was reported by prisoners with current risk for suicide when compared to those with no risk. These results show that how prisoners perceive their quality of life in prison is an important component associated with suicidal behaviour in prison. Strategies oriented towards the enhancement of adaptation to prison environment can, therefore, represent effective preventive strategy lowering the risk for suicide.

Since there was a lack of knowledge in regard to suicidal behaviour in male prisoners, especially in Slovenian prison system, our research that included more than one-third of all prisoners in Slovenia allowed as to describe characteristics of suicidal behaviour and quality of life in prison connected to it for this specific at-risk group more thoroughly, since previously there was no such research done in Slovene prisons. This gives potentially useful information on aspects of the prison environment that 
can affect suicidal behaviour, since information gained in studies from other countries might not be relevant to the Slovene population of prisoners, due to differences in prison systems.

However, this study presents some limitations. Since for some of the participants Slovene was not the first language, they could have problems in understanding the questions, and this could affect their answers and therefore also the collected data. In addition, some participants also had some problems with understanding the questions due to low intellectual functioning. Some participants also had problems with reading and they, therefore, needed assistance, which might have affected their answers. Due to prison restrictions and policies, we had also some problems to include detained individuals into the research, therefore, the proportion between convicted prisoners and detained individuals in our sample was not consistent with the population, containing higher percentage of convicted prisoners and lower percentage of detained individuals, which can affect the data, since detained individuals seem to be at specific risk for suicide.

Nevertheless, this research represents a possible step toward better understanding quality of life and suicidal behaviour in Slovene prisons. Furthermore, information gained can help us improving preventive strategies and interventions in the prison system, and the new knowledge can also be used in the development of future guidelines for effective preventive activities for male prisoners. 


\section{Disclosure statement}

No potential conflict of interest was reported by the authors.

\section{Funding}

This study was partially funded by the Slovenian Research Agency (MR 36480 and J5-8244). 


\section{References}

Barker, E., Kõlves, K., \& De Leo, D. (2014). Management of suicidal and self-harming behaviors in prisons: systematic literature review of evidence-based activities. Arch Suicide Res, 18(3), 227240.

Biggam, F. H., \& Power, K. G. (1997). Social Support and Psychological Distress in a Group of Incarcerated Young Offenders. International Journal of Offender Therapy and Comparative Criminology, 41(3), 213-230. http://doi.org/10.1177/0306624X97413002

Carcedo, R. J., López, F., Begoña Orgaz, M., Toth, K., \& Fernández-Rouco, N. (2008). Men and Women in the Same Prison. International Journal of Offender Therapy and Comparative Criminology, 52(6), 641-657. http://doi.org/10.1177/0306624X07311596

Carcedo, R. J., Perlman, D., López, F., \& Orgaz, M. B. (2012). Heterosexual Romantic Relationships , Interpersonal Needs, and Quality of Life in Prison, 15(1), 187-198.

Carcedo, R. J., Perlman, D., Orgaz, M. B., López, F., \& Fernández-Rouco, N. (2011). Heterosexual Romantic Relationships Inside of Prison : Partner Status as Predictor of Loneliness, Sexual Satisfaction , and Quality of Life. http://doi.org/10.1177/0306624X10373593

Fazel, S., \& Danesh, J. (2002). Serious mental disorder in 23000 prisoners : a systematic review of 62 surveys. The Lancet, 359, 545-550.

Kerkhof, A. J., \& Bernasco, W. (1990). Suicidal behavior in jails and prisons in The Netherlands: incidence, characteristics, and prevention. Suicide Life Threat Behav, 20(2), 123-137.

Lovibond, S. H., \& Lovibond, P. F. (1995). Manual for the depression anxiety stress scales. Sidney: Psychology Foundation.

Nobile, C. G., Flotta, D., Nicotera, G., Pileggi, C., \& Angelillo, I. F. (2011). Self-reported health status and access to health services in a sample of prisoners in Italy. BMC Public Health, 11(1), 529. http://doi.org/10.1186/1471-2458-11-529

Nurse, J., Woodcock, P., \& Ormsby, J. (2003). Influence of environmental factors on mental health within prisons: focus group study. BMJ, 327(7413), 480-483.

http://doi.org/10.1136/bmj.327.7413.480

Paykel, E. S., Myers, J. K., Lindenthal, J. J., \& Tanner, J. (1972). Suicidal feelings in the general population: a prevalence study. Br J Psychiatry, 124, 380-406.

Poštuvan, V., \& Madjar, T. (2013). Ethical issues of mental health care in slovene prison system. In N. Konrad, B. Völlm, \& D. N. Weisstub (Eds.), Ethical issues in prison psychiatry (pp. 294-314). Dordrecht: Springer.

Prison Administration of the Republic of Slovenia. (2003). Annual report 2002. Retrieved from http://www.mp.gov.si/fileadmin/mp.gov.si/pageuploads/UIKS/Letna_porocila/porocilo_uiks_2 002.pdf

Rimkeviciene, J., Hawgood, J., O'Gorman, J., \& De Leo, D. (2015). Personal Stigma in Suicide Attempters. Death Studies, 39(10), 592-599. http://doi.org/10.1080/07481187.2015.1037972

Salize, H. J., Dreßing, H., \& Kief, C. (2007). Mentally Disordered Persons in European Prison Systems Needs, Programmes and Outcome (EUPRIS). Mannheim.

Schafer, N. E. (1994). Exploring the Link between Visits and Parole Success: A Survey of Prison 
Visitors. International Journal of Offender Therapy and Comparative Criminology, 38(1), 17-32. http://doi.org/10.1177/0306624X9403800103

Togas, C., Raikou, M., \& Niakas, D. (2014). An Assessment of Health Related Quality of Life in a Male Prison Population in Greece Associations with Health Related Characteristics and Characteristics of Detention. BioMed Research International, 2014, 1-9. http://doi.org/10.1155/2014/274804

URSIKS. (2017). Letno poročilo (Yearly report) 2016. Ljubljana. Retrieved from http://www.mp.gov.si/si/o_ministrstvu/ursiks_organ_v_sestavi/dokumenti/letna_porocila/

Van Orden, K. A., Witte, T. K., Cukrowicz, K. C., Braithwaite, S. R., Selby, E. A., \& Joiner, T. E. (2010). The interpersonal theory of suicide. Psychological Review, 117(2), 575-600. http://doi.org/10.1037/a0018697

White, T. W., Schimmel, D. J., \& Frickey, R. (2002). A comprehensive analysis of suicide in federal prisons: a fifteen-year review. J Correct Health Care, 9, 321-345.

WHO. (1996). WHOQOL-BREF: Introduction, administration, scoring and generic version of the assessment. Geneva: Programme on Mental Health World Health Organization.

WHO. (1998). Wellbeing measures in primary health care. The depcare project. Report on a WHO Meeting. Stockholm: WHO Regional Office for Europe.

WHO. (2013). Good governance for prison health in the 21st century. A policy brief on the organization of prison health.

Zver Makovec, M., \& Madjar, T. (2017). Prison suicide prevention programme in Slovenia. In 8th TRIPLE i: Intuition, Imagination and Innovation in Suicidology Conference - Programme and Abstract Book (p. 14). 
Table 1.

Comparison of feelings of depression, anxiety and stress between prisoners with current risk for suicide and those not at risk.

\begin{tabular}{|c|c|c|c|c|c|c|c|c|}
\hline \multirow[t]{3}{*}{ DASS21 } & \multicolumn{4}{|c|}{ Current risk for suicide } & \multirow[t]{3}{*}{$U$} & \multirow[t]{3}{*}{$\mathrm{z}$} & \multirow[t]{3}{*}{$p$} & \multirow[t]{3}{*}{$r$} \\
\hline & \multicolumn{2}{|c|}{ Yes } & \multicolumn{2}{|c|}{ No } & & & & \\
\hline & M & SD & M & SD & & & & \\
\hline Depression & 1.67 & 0.91 & 0.60 & 0.66 & 12.14 & 6.93 & $0.00 *$ & 35.0 \\
\hline Anxiety & 1.59 & 0.93 & 0.57 & 0.66 & 11.93 & 6.58 & $0.00 *$ & 33.1 \\
\hline Stress & 1.79 & 0.88 & 0.76 & 0.70 & 11.95 & 6.57 & $0.00 *$ & 33.1 \\
\hline
\end{tabular}

*Mann-Whitney $\mathrm{U}$ test is significant at the 0.01 level.

Table 2.

Comparison of quality of life and well-being between prisoners with current risk for suicide and those not at risk.

\begin{tabular}{|c|c|c|c|c|c|c|c|c|c|}
\hline & & \multicolumn{4}{|c|}{ Current risk for suicide } & \multirow[t]{3}{*}{$\mathrm{t}$} & \multirow[t]{3}{*}{$\mathrm{df}$} & \multirow[t]{3}{*}{$\mathrm{p}$} & \multirow[t]{3}{*}{$r$} \\
\hline & & \multicolumn{2}{|c|}{ Yes } & \multicolumn{2}{|c|}{ No } & & & & \\
\hline & & M & SD & M & SD & & & & \\
\hline \multirow[t]{6}{*}{ WHOQOL-BREF } & Physical health & 2.94 & 0.58 & 3.35 & 0.54 & 4.636 & 401 & $0.00 *$ & 0.22 \\
\hline & Psychological health & 3.14 & 0.81 & 3.71 & 0.56 & 4.492 & 400 & $0.00^{*}$ & 0.22 \\
\hline & Social relations & 2.76 & 1.08 & 3.51 & 0.95 & 4.783 & 399 & $0.00 *$ & 0.23 \\
\hline & Environment & 2.59 & 0.83 & 3.38 & 0.75 & 6.505 & 401 & $0.00 *$ & 0.31 \\
\hline & Overall quality of life & 2.26 & 1.12 & 3.39 & 1.01 & 6.840 & 394 & $0.00 *$ & 0.32 \\
\hline & Overall health & 2.72 & 1.45 & 3.74 & 1.08 & 4.442 & 395 & $0.00 *$ & 0.22 \\
\hline WHO5 & & 33.30 & 26.62 & 60.67 & 24.32 & 6.901 & 399 & $0.00 *$ & 0.33 \\
\hline
\end{tabular}


Figure 1: Means for 4 items on PSS scale reporting different types of suicidal behaviour split by social contact changes reported by prisoners.

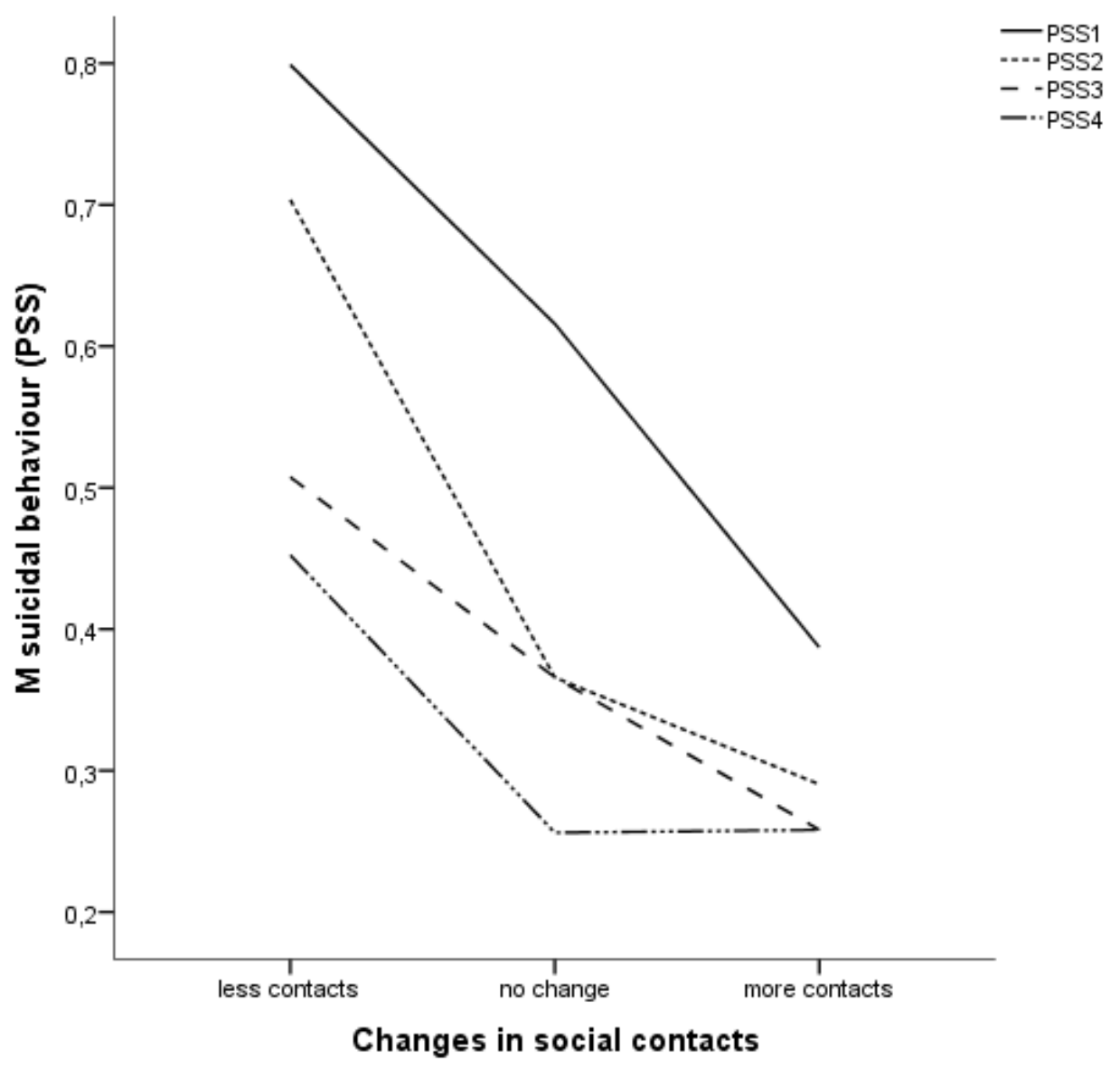


Figure 2: Boxplot on thwarted belongingness and perceived burdensomeness split by current risk for suicide.
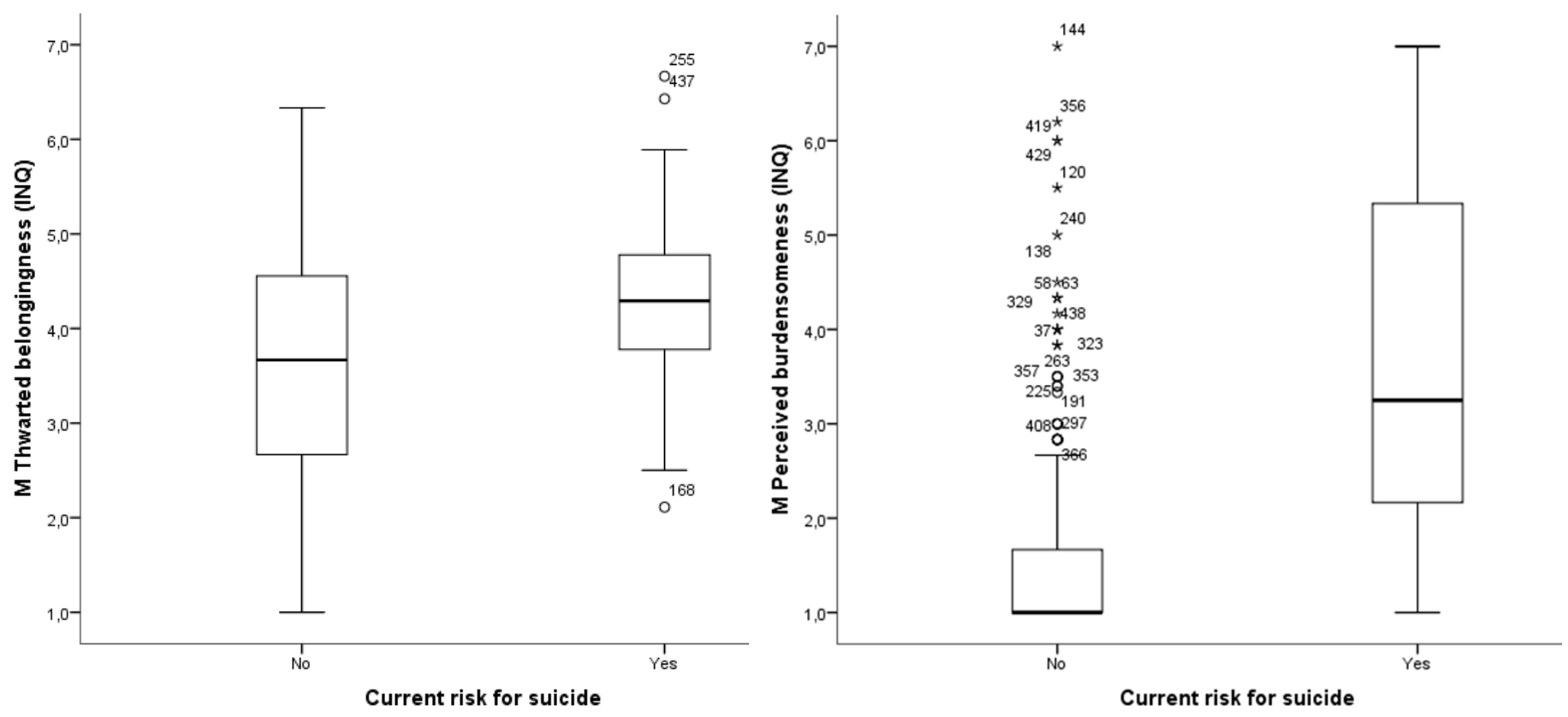